\title{
Correction to: On a question of f-exunits in $\mathbb{Z} / n \mathbb{Z}$
}

\author{
Anand, Jaitra Chattopadhyay, and Bidisha Roy
}

Correction to: Arch. Math. https://doi.org/10.1007/s00013-020-01558-w.

Unfortunately, the corresponding author was published incorrectly in the original article. The correct corresponding author is Dr. Bidisha Roy.

Publisher's Note Springer Nature remains neutral with regard to jurisdictional claims in published maps and institutional affiliations.

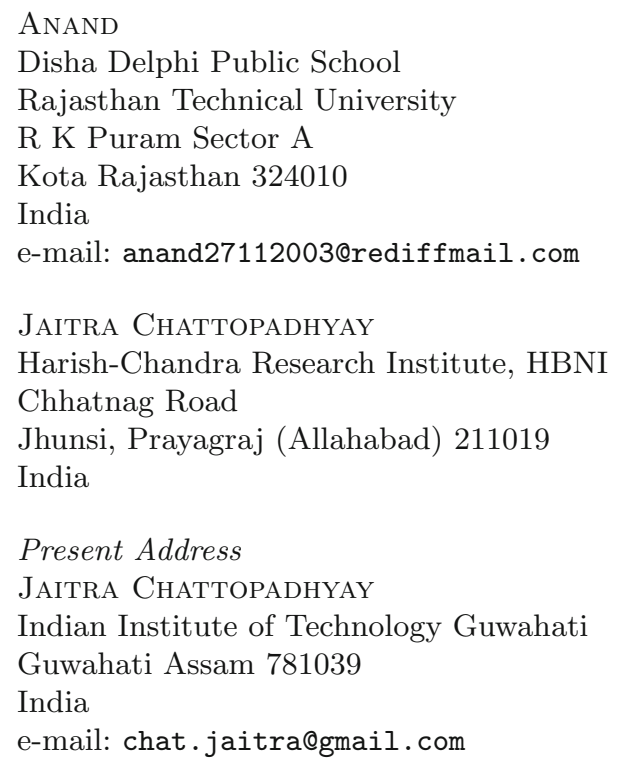

The original article can be found online at https://doi.org/10.1007/s00013-020-01558-w. 


\section{Bidisha Roy}

School of Mathematics

Tata Institute of Fundamental Research

Homi Bhabha Road, Navy Nagar, Colaba

Mumbai Maharashtra 400005

India

e-mail: brroy123456@gmail.com 